\title{
A INFLUÊNCIA DA AUTORREGULAÇÃO NAS HEURÍSTICAS E VIESES UTILIZADOS NO PROCESSO DE TOMADA DE DECISÃO
}

\section{1- Fábio Pimenta de Pádua Júnior}

Doutor em Administração pela Universidade Federal do Paraná (UFPR), Brasil.

Pós-doutorando pelo Programa de Pós-Graduação em Administração da Universidade Federal do Paraná (PPGADM/UFPR) pimenta70@gmail.com

http://lattes.cnpq.br/3244049829793253

\section{2- Pedro José Steiner Neto}

Doutor em Administração pela Universidade de São Paulo (USP), Brasil.

Professor do Programa de Mestrado e Doutorado da Universidade Positivo (PMDA/UP), Brasil.

pedrosteiner@ufpr.br

http://lattes.cnpq.br/8347081803216649

\section{3- Edson Melo da Silva Filho}

Mestre em Administração pela Universidade Federal de Santa Catarina (UFSC), Brasil.

Professor das Faculdades SPEI, Brasil.

edsonmelo29@hotmail.com

http://lattes.cnpq.br/3063653145391146

\section{4- Maximiliano Gonetecki de Oliveira}

Mestre em Administração pela Universidade Federal do Paraná (UFPR), Brasil.

Professor do Centro Universitário Franciscano do Paraná, Brasil.

max@magox.com.br

http://lattes.cnpq.br/7875635834110554

\author{
Diego Maganhotto Coraiola - Editor Geral \\ Editor responsável pela submissão: \\ Salomão de Farias. \\ Artigo analisado via processo de revisão duplo cego (Double-blind). \\ Recebido em: 26/06/2014 \\ Aprovado em: 18/12/2014 \\ Última Alteração: 26/01/2015
}

* Contato Principal: Alameda Princesa Izabel, 2500, ap. 406. Bigorrilho, Curitiba - PR, Brasil. CEP: 80730-080. 
A INFLUÊNCIA DA AUTORREGULAÇÃO NAS HEURÍSTICAS E VIESES UTILIZADOS NO PROCESSO DE TOMADA DE DECISÃO

\title{
ABSTRACT
}

Entre as diferentes teorias heurísticas que visam explicar o processo decisório, este estudo explora a falácia do jogador e a teoria da mão-quente. O objetivo deste artigo é investigar a influência da autorregulação afetiva nas heurísticas e vieses utilizados no processo de tomada de decisão. Foram realizados dois experimentos. No primeiro, foi avaliado se os resultados anteriores de ganhos com ações de empresas afetavam a preferência dos consumidores pela compra ou venda dessas ações. Constatou-se diferença entre gêneros no processo decisório, com a ocorrência da falácia do jogador para a amostra masculina, mas não para a amostra feminina. O segundo experimento foi realizado com o intuito de verificar o papel da autorregulação nestas heurísticas. Após a indução de autorregulação, observou-se a ocorrência da falácia do jogador e o viés da mão quente em algumas condições, indicando alterações nas decisões tomadas pelos consumidores. A partir desses resultados, conclui-se que há uma influência significativa do estado afetivo nas tomadas de decisão e que as mulheres são menos suscetíveis à falácia do jogador do que os homens.

\section{Keywords}

Autorregulação; tomada de decisão; falácia do jogador; teoria da mão quente.

\section{THE INFLUENCE OF SELF-REGULATION IN HEURISTICS AND BIASES USED IN CONSUMER DECISION MAKING}

\begin{abstract}
RESUMO
Among the different heuristics theories that attempt to explain the decision making process, this study explores the gambler's fallacy and the hot hand theory. This paper investigates the influence of self-regulation in heuristics and biases used during consumer decision making. Two experiments were conducted. The first one assessed if results of past performance of stocks affected consumer preference to buy or sell those stocks. Results indicated a significant difference between gender in decision making, with the occurrence of the gambler's fallacy for the male sample, but not for the female sample. The second experiment investigated the role of self-regulation in the gambler's fallacy and hot hand bias. Results showed that after the induction of self-regulation, it was noticed the gambler's fallacy and the hot hand theory in some conditions, indicating changes in the decisions made by consumers. We conclude that there is a significant influence of affective state in decision making and that women are less susceptible to the gambler's fallacy than men.
\end{abstract}

Palavras-Chave

Self-regulation; decision making; gambler's fallacy; hot hand theory. 


\section{Introduction}

A tomada de decisão é inerente a todo indivíduo, visto que a todo instante as pessoas tomam decisões, sejam elas de modo consciente ou não. Algumas decisões são fáceis e corriqueiras, tais como as envolvidas na decisão de compra do alimento matinal para o café da manhã ou a escolha do melhor caminho para o trabalho evitando o trânsito. Outras são mais complexas, requerem maior envolvimento do consumidor e podem possuir elevado grau de incerteza, tais como a escolha de uma profissão, de uma universidade, a compra de um imóvel ou decisões sobre investimento no mercado de ações. Boa parte dos métodos, que ajudam as pessoas a tomarem decisões sob condições de incerteza, requerem algum grau de estimativa de probabilidades dos possíveis resultados. Considerando que é muito difícil realizar o cálculo exato das probabilidades envolvidas, estas acabam sendo estimadas de modo subjetivo pelas pessoas (Goodwin \& Wright, 2000). Diversas decisões são baseadas em crenças sobre a probabilidade de eventos incertos, tais como o resultado de uma eleição ou o valor futuro do dólar. Essas crenças, às vezes, são expressas em forma numérica, como possibilidades ou probabilidades subjetivas. As pessoas confiam em um número limitado de princípios heurísticos para reduzir a complexa tarefa de calcular probabilidades e predizer valores para simples operações de julgamento (Tversky \& Kahneman, 1974, 2000). Em muitas situações, ocorre uma superestimação do resultado (Bower, 2010).

Para alguns pesquisadores, a tomada de decisão era vista como um processo apenas cognitivo, o qual era realizado de modo racional e tinha como objetivo maximizar a utilidade das escolhas. Entretanto, recentemente, o papel das emoções tem recebido crescente destaque nas pesquisas sobre tomadas de decisão. Os principais resultados desses trabalhos indicam que mesmo o afeto incidental - o qual não é relacionado com a decisão em questão - pode ter um impacto significativo no julgamento e na escolha. Além disso, deficiências emocionais, sejam elas inatas ou induzidas, podem degradar a qualidade da tomada de decisão. Por fim, a inclusão do afeto nos modelos de tomada de decisão pode expandir significativamente o poder de explicação dos mesmos (Loewenstein \& Lerner, 2003). Pesquisas em neuroeconomia mostram que as áreas do cérebro que geram estados emocionais também processam informações sobre riscos, recompensas e punições, o que sugere que as emoções influenciam as decisões financeiras de uma forma previsível e parcimoniosa (Kuhnen \& Knutson, 2011). Kuhnen e Knutson (2011) encontraram evidências de que os estados emocionais positivos como excitação, por exemplo, induzem as pessoas a assumirem riscos e a ficarem confiantes sobre sua habilidade em avaliar opções de investimento, ao passo que as emoções negativas, como ansiedade, têm o efeito oposto. As crenças são atualizadas, de modo a manter um estado emocional positivo, ignorando informações que contradizem as escolhas anteriores dos indivíduos. Características de mercado ou resultados de escolhas passadas podem mudar as emoções e, assim, influenciar futuras decisões financeiras.

Estudos realizados sobre a teoria do foco regulatório encontraram evidências de que o foco em prevenção conduz a pessoa a evitar problemas que possam impedir um estado final desejado, ao passo que o foco em promoção faz com que a pessoa encontre formas de aproximar-se de um estado final desejado (Crowe \& Higgins, 1997; Higgins et al., 1994; Shah et al., 1998; Silva, 2011). A partir desta teoria, acredita-se que um sujeito com foco em promoção ou prevenção utilizará estratégias mentais distintas para buscar um determinado resultado, o que poderá influenciar os vieses e heurísticas utilizados em suas tomadas de decisão.

No mercado financeiro, apesar de muitos analistas econômicos afirmarem que performances passadas não são garantia de bons retornos no futuro, os consumidores acabam confiando em informações de sequências de determinados resultados para tomarem suas decisões de investimentos (Rabin \& Vayanos, 2010). É comum as instituições financeiras disponibilizarem tabelas com históricos de rentabilidades de seu portfólio (ver Johnson \& Tellis, 2005). Tendo por base essas informações, faz-se oportuno os seguintes questionamentos: Ao escolher onde investir, os consumidores são realmente influenciados pelo histórico dos fundos de investimento? Outros fatores poderiam influenciar essa decisão?

O presente trabalho aborda estas questões e tem como objetivo principal avaliar a influência da autorregulação na tomada de decisão quando estas decisões estão sendo influenciadas pela falácia do jogador e pela teoria da mão quente. Outro objetivo é explorar a diferença de gênero nessas condições. Na primeira parte é apresentada uma revisão da literatura sobre o tema, incluindo a falácia do jogador, a teoria da mão quente e a teoria do foco regulatório. Em seguida, é feita uma explanação sobre a metodologia utilizada. Os resultados são apresentados na sequência e a primeira etapa dos resultados avalia a influência das heurísticas e vieses utilizados pelos consumidores durante a tomada de decisão. Mais especificamente, busca avaliar se os resultados anteriores de 
ganhos de ações de empresas afetam a preferência dos consumidores pela compra ou venda destas ações, com o propósito de verificar a ocorrência da falácia do jogador e da teoria da mão quente. A segunda etapa avalia a influência da autorregulação no viés da falácia do jogador e da teoria da mão quente, ou seja, se a mudança de estado afetivo influencia esta ou aquela teoria. Na parte final do trabalho são apresentadas a discussão dos resultados, as considerações finais, as limitações do estudo e algumas sugestões para futuras pesquisas.

\section{Quadro Teórico}

\subsection{Falácia do Jogador}

Dentre as diferentes teorias heurísticas que visam explicar o processo decisório, destacam-se a falácia do jogador e a teoria da mão quente (Bower, 2010). Ambas baseiam-se na tendência humana em julgar, referenciando-se por eventos históricos, mesmo quando a relação for probabilisticamente inexistente (Gilovich et al., 1985; Loh \& Warachka, 2012; Tversky \& Kahneman, 1971). A tomada de decisão envolvendo eventos independentes é muitas vezes tendenciosa e afetada por resultados anteriores (Xue et al., 2011). Supõe-se que a lógica envolvida nesse processo esteja relacionada com o erro de percepção de um sujeito ao inferir que uma pequena amostragem possa explicar uma tendência real (Lyons et al., 2013). Uma possível explicação para os dois fenômenos é a incapacidade de uma pessoa em perceber os eventos como sendo probabilisticamente isolados (Kahneman \& Tversky; 1972; Lyons et al., 2013).

A falácia do jogador baseia-se no fato de que, após uma série de eventos aleatórios relacionados a um fenômeno em observação obterem o mesmo resultado - ou um resultado que sugira uma tendência - o indivíduo julga que em determinado momento o próximo resultado deverá ser contrário ao obtido anteriormente. Deste modo, contraria-se uma importante perspectiva da estatística que afirma a independência probabilística entre tais eventos (Tversky \& Kahneman, 1971). A falácia do jogador é um fenômeno que parece surgir sempre que o indivíduo faz predições sobre eventos randômicos (Roney \& Trick, 2009). A falácia do jogador é tipicamente manifestada pela crença de que um evento aleatório tem maior probabilidade de ocorrer porque não tem acontecido por um determinado período de tempo, ao passo que um evento randômico é menos provável de ocorrer porque aconteceu recentemente (Lyons et al., 2013). A falácia do jogador também é conhecida como o princípio da maturidade das chances (Clotfelter \& Cook, 1993) ou lei da maturidade (Bonassi et al., 2008).

Para ilustrar a teoria, pode-se supor um jogo de cara ou coroa. Após algumas ocorrências seguidas com o resultado cara, o jogador tende a acreditar que as chances do próximo resultado ser coroa são maiores. Essa falácia surge porque as pessoas não se atentam para o fato de que cada jogada representa um evento independente (Tversky \& Kahneman, 1971). No estudo de Roney e Trick (2003) essa presunção é corroborada. Todavia, os autores descobriram que a falácia do jogador poderia ser eliminada caso a jogada crítica fosse arbitrariamente designada como a primeira jogada de uma nova série de jogadas.

Clotfelter e Cook (1993) utilizaram jogos de loterias para evidenciar que a crença na dependência negativa influencia os padrões de apostas de determinados números. Os autores descobriram que a quantidade de dinheiro apostada em um número em particular tende a cair drasticamente após o mesmo ter sido sorteado. Entretanto, após vários meses, aquele número volta gradualmente ao padrão normal de apostas, o que evidencia a ocorrência da falácia do jogador em uma situação real.

Em ocasiões em que são realizadas apostas, presume-se que a falácia do jogador ocorrerá tanto nos casos de ganho quanto de perda. Um jogador, após sofrer uma derrota, tenderá a imaginar que suas chances de vencer serão maiores na aposta subsequente. Jogadores de pôquer, que atuam em conformidade com a falácia do jogador, podem ser menos suscetíveis a fazer apostas após terem obtido ganhos e mais agressivos em suas apostas depois de terem sofrido uma perda prévia (Smith et al., 2009). Esse comportamento em questão também foi analisado no mercado financeiro, mostrando que investidores vendem ações com tendência de alta muito cedo e acabam segurando ações em queda por muito tempo (Johnson \& Tellis, 2005; Xue et al., 2011). Kudryavtsev et al. (2013) analisaram o efeito de cinco vieses comportamentais - entre eles a falácia do jogador e a falácia da mão quente - na tomada de decisão no mercado acionário. Demonstraram que os investidores ativos no mercado de ações exibem graus moderados dos vieses comportamentais. Verificaram, ainda, que se um investidor aceita empregar uma certa técnica de tomada de decisão intuitiva, ele provavelmente, aceitará todas as outras também. 
Portanto, a falácia do jogador pode ser entendida, de forma abrangente, como a crença equivocada de que a probabilidade de um evento ocorrer é menor quando aquele evento ocorreu repetidas vezes recentemente, mesmo que a probabilidade entre os eventos seja independente.

\subsection{Teoria da Mão Quente}

Com uma heurística similar, a teoria da mão quente sugere uma correlação positiva entre os eventos randômicos anteriores e o evento imediatamente seguinte. A expressão "mão quente" foi originalmente, utilizada por Gilovich et al. (1985) para descrever como observadores acreditavam em determinados padrões relacionados com o desempenho dos jogadores de basquetebol. Essas pessoas acreditavam que os jogadores com uma sequência de acertos nos arremessos prévios tinham uma maior chance de acertar o arremesso seguinte, mesmo que o desempenho fosse apenas decorrente do acaso. De forma similar à falácia do jogador, a decisão do sujeito sobre o evento é baseada em um histórico de resultados, empiricamente comprovados, serem estatisticamente independentes. Conforme ressaltam Crosson e Sundali (2005), a falácia da mão quente é a crença na autocorrelação positiva de uma sequência aleatória que não é autocorrelacionada.

Yuan et al. (2014) investigaram se as pessoas poderiam ser influenciadas a tomar decisões de investimento baseadas em sinais de choques aleatórios sem significado. Eles encontraram evidências de que os indivíduos apresentaram sistematicamente o comportamento da falácia da mão quente ao perseguir os ganhadores que haviam escolhido os números vencedores da rodada anterior em um jogo de loteria.

Vários estudos avaliaram o efeito da mão quente. Boa parte destas pesquisas não encontrou evidências concretas da existência deste efeito (Gilovich et al., 1985; Koehler \& Conley, 2003), ao passo que outras afirmam terem encontrado evidências do efeito da mão quente em esportes que requerem grande habilidade (Arkes \& Martinez, 2011; Yaari \& Eisenmann, 2011 ).

Esse fenômeno também foi observado no mercado financeiro. Segundo o estudo de Sirri e Tufano (1998), empresas que administram fundos de investimento que apresentaram resultados sequenciais positivos de retorno aos seus investidores, possuíam maiores volumes de novos investimentos. Aparentemente, essa situação levou o Security and Exchange Comission (SEC) a obrigar os gestores de fundos a divulgar uma nota em suas comunicações publicitárias afirmando que resultados anteriores não são garantia de resultados futuros (Johnson \& Tellis, 2005).

Ao observar essa dissonância entre as duas teorias, Johnson e Tellis (2005) realizaram experimentos que permitiram a conclusão de que elas não são mutuamente excludentes, mas complementares. Assim, em uma sequência de eventos históricos, a variável que ditará qual das falácias entrará em ação é o tamanho da sequência de eventos. Em suma, quanto menor a quantidade de eventos observados, ou do histórico disponível, maior será a chance de uma pessoa assumir um comportamento condizente com a teoria da mão quente. Em contrapartida, conforme a quantidade de observações similares aumentar, maior será a chance da falácia do jogador influenciar a tomada de decisão do sujeito.

Dong et al. (2014) criaram uma tarefa para simular um jogo de apostas o mais próximo possível da realidade, para examinar os efeitos de resultados prévios em decisões subsequentes. Por meio da análise comportamental e de imagens neurológicas obtidas por fMRI, os autores descobriram que os participantes, durante as rodadas de perda, tomavam decisões apresentado um padrão semelhante à da falácia do jogador. Durante as rodadas de ganho, os participantes tendiam a seguir as decisões vencedoras anteriores, comportamento semelhante à da falácia da mão quente.

Em outro estudo sobre a falácia do jogador e a falácia da mão quente, Xu e Harvey (2014) avaliaram apostas relativas ao esporte realizadas on-line e demonstraram que os padrões de apostas dependem da sequência de ganhos ou perdas. Pelo fato de acreditar na falácia do jogador ou seja, uma reversão na sequência de ganhos ou perdas - os apostadores apresentaram uma tendência a fazer apostas mais seguras depois de ganhar. Isto, por sua vez, ocasionou um aumento da probabilidade deles continuarem a vencer. Por outro lado, os apostadores perdedores acreditavam que a sorte deles iria mudar e, por conta disto, faziam apostas mais arriscadas. Isto fez com que aumentasse a probabilidade deles continuarem a perder. Os autores concluem que, por acreditar na falácia do jogador, os apostadores acabaram criando sua própria mão quente.

Os resultados das pesquisas sobre este tema instigam maiores reflexões sobre o papel de outros elementos conhecidos do processo decisório do indivíduo, tendo em vista que surgem suspeitas de que não seja somente o histórico de observações o elemento chave na ativação de um 
dos dois mecanismos decisórios. Considerando o contexto do mercado acionário e a falácia do jogador, é apresentada a seguinte hipótese de pesquisa, na qual o sujeito busca manter um investimento rentável:

H1: Diante de resultados com uma sequência de ganhos positivos para uma ação, a preferência dos consumidores para a compra (venda) da ação irá primeiro aumentar (diminuir) para uma pequena sequência de ganhos positivos, mas depois de um ponto crítico, a preferência dos consumidores para a compra (venda) da ação irá eventualmente diminuir (aumentar).

Croson e Gneezy (2009) revisaram a literatura sobre as diferenças de gênero em experimentos na área de economia. Os autores identificaram diferenças robustas nas preferências de risco. As mulheres são mais avessas ao risco do que os homens. Além disso, as mulheres também são mais avessas à competição do que os homens. Suetens e Tyran (2012) estudaram a diferença de gêneros na falácia do jogador usando dados da loteria estadual da Dinamarca. Os autores encontraram evidências da ocorrência da falácia do jogador para homens, mas não para mulheres. Isto significa que as mulheres não levam em consideração os resultados dos jogos da semana anterior ao realizar suas apostas na loteria. Com base nestes estudos, é proposta a seguinte hipótese de pesquisa:

H2: A falácia do jogador ocorrerá somente para os consumidores do sexo masculino, sendo que as mulheres não serão afetadas pelo histórico de eventos anteriores.

Com o intuito de ir além dessas observações, em busca de outras variáveis envolvidas no processo decisório, resgatam-se as estratégias de motivação e ação do indivíduo. Assim, para uma melhor compreensão dos processos envolvidos, sugere-se a observação do papel do Foco Regulatório no desencadeamento da relação entre as duas teorias apresentadas.

\subsection{Foco Regulatório}

Para compreender determinados fenômenos comportamentais, uma incógnita recorrente são as explicações das razões que motivam a ação. Os consumidores, como seres racionais, presumidamente possuem um padrão cognitivo baseado em diversas estruturas que sustentam suas decisões.

A questão motivacional é discutida na literatura de psicologia, amparada tradicionalmente pelo princípio hedonista, e o estudo dos princípios subjacentes que exploram sua operação: antecipação regulatória, referência regulatória e foco regulatório. A lógica hedonista baseia-se no pressuposto de que todos procuram o prazer, motivando-se com as experiências que tragam esse resultado e evitem a dor concomitantemente (Aaker \& Lee, 2001).

Assim, os princípios regulatórios, que exploram o processo que motiva o sujeito a buscar determinado estado final, permeiam o engajamento do sujeito com sua meta (Higgins, 1997). Além disso, Freitas e Higgins (2002) e Fishbach e Ferguson (2007) argumentam que o envolvimento com a meta está baseado na teoria do foco regulatório e esta tem como elemento chave a autorregulação.

A autorregulação diz respeito às estratégias que a pessoa utiliza para atingir a meta. Liberman et al. (1999) indicam a existência de duas estratégias subjacentes, a promocional e a preventiva. A primeira descreve um foco no resultado positivo, envolvendo um foco regulatório com essa perspectiva. A segunda volta-se para um resultado negativo e regula o foco decorrente desse. Nesta última, o sujeito desenvolverá estratégias que o afastem do resultado, enquanto naquela o caminho utilizado será da aproximação (Higgins et al., 1994; Crowe \& Higgins, 1997; Shah, et al., 1998).

O estudo de Freitas e Higgins (2002) mostra que existe uma diferença entre o sujeito que utiliza o foco promocional que tem como característica motivacional situações nas quais se busca aproximar da meta, contraposto ao indivíduo que utiliza o foco preventivo em que a meta justamente é afastar-se de determinado objetivo. Seria a diferença entre "eu quero ser magro" e "eu não quero engordar".

Lee et al. (2014) exploraram a influência do foco regulatório na atratividade percebida de dois tipos de precificação. Os resultados de quatro estudos indicaram que consumidores com foco em promoção - e não em prevenção - apresentaram uma preferência maior por preços particionados (preço do produto e preço de uma taxa mostrados separadamente) do que os preços combinados (somatória dos preços). Isto representa que um foco em promoção conduz a um processamento global, ou seja, as pessoas tendem a confiar mais em características primárias e mais relevantes de um certo estímulo ao tomar decisões (Trope \& Liberman, 2010). 
Cada pessoa carrega um determinado foco regulatório crônico (Higgins, 1997). Esse mecanismo é a chave que direciona qual tipo de estímulo tenderá a ser mais bem aceito pelo sujeito e qual a lógica que permeia sua motivação. Entretanto, esse foco pode ser manipulado (Freitas et al., 2002).

A teoria do foco regulatório já foi estudada na perspectiva da influência das emoções, no caso de antecipação dessas, com a orientação regulatória do sujeito, propondo uma miscigenação do princípio antecipatório com o foco regulatório (Higgins, 1997, 1999). A aplicação dessa lógica é que um resultado negativo geraria emoções negativas, fazendo com que o sujeito previsse resultados negativos e, consequentemente, alterasse o foco regulatório para preventivo. Por outro lado, o sucesso causaria emoções positivas e, consequentemente, previsões positivas e a alteração do foco para promocional (Silva, 2011). As emoções possuem um efeito importante na presunção de riscos em investimentos financeiros (Kuhnen \& Knutson, 2011).

Xi et al. (2014) avaliaram o papel da motivação em promoção na tomada de decisão. Usando um modelo de investimento em ações, em que os indivíduos acreditavam que estavam tomando decisões que eram reais, verificou-se que o foco em promoção - e não em prevenção - foi um preditor da alternância entre escolhas arriscadas e conservadores no que diz respeito a ganhos. Os participantes com foco em promoção escolheram uma opção relativamente arriscada quando sua carteira de ações permaneceu inalterada, mas mudaram para uma opção relativamente conservadora quando eles tinham acabado de experimentar um grande ganho.

A expectativa de um resultado positivo irá motivar uma decisão favorável àquela ação, enquanto o oposto irá desmotivar. Nas teorias da falácia do jogador e da mão quente, pode-se supor que o sujeito com foco promocional tenderá a se arriscar mais, ao passo que o foco preventivo fará com que a pessoa tenha tendência a evitar riscos.

Quando diferentes focos regulatórios são estimulados em um sujeito, está sendo induzida a autorregulação (Viacava, 2012). Como consequência desta autorregulação, o foco na meta de consumo principal é elevado, fazendo com que o consumidor mantenha o direcionamento, o foco e os esforços para atingir esta meta de consumo.

É importante destacar que, a partir da perspectiva do foco regulatório, a busca ou aversão pelo risco não são traços de personalidade. São táticas que servem a diferentes motivações e serão escolhidas dependendo se o motivo que está atualmente ativo tem foco em promoção ou prevenção. Além disso, a ativação do sistema de promoção ou de prevenção não depende apenas da personalidade, pois cada foco pode ser induzido em uma determinada situação (Xi et al., 2014).

Desta forma, supõe-se que um consumidor com autorregulação terá influência da falácia do jogador, pois sua estratégia de ação está direcionada para sua meta principal. Entretanto, ao aumentar o tamanho da sequência de eventos, sua influência passará a ser da falácia da mão quente. Assim, pressupõe-se que:

H3: Para uma sequência de ganhos crescentes, a intenção de compra (venda) de ações pelos consumidores com indução de foco regulatório aumenta (diminui) conforme aumenta o número de trimestres da sequência de ganhos apresentada. Depois de um determinado ponto crítico, a intenção de compra (venda) estabiliza-se.

\section{Procedimentos Metodológicos}

Para testar as hipóteses propostas neste estudo foram realizados dois experimentos. O método experimental é o mais indicado quando se deseja confirmar ou refutar relações causais hipotéticas entre variáveis (Lehmann et al., 1998).

Experimento é uma metodologia na qual uma intervenção é introduzida para observar seus efeitos, sendo feito de modo deliberado (Shadish et al., 2002). Procura-se investigar o efeito de $X$ em $Y$, em que $X$ é a variável independente e $Y$ é a variável dependente, de modo que o pesquisador tenha controle completo sobre o fator "manipulado" $(X)$ e possa, alterando $X$, avaliar o resultado provocado em Y (Goodwin, 2008).

Há dois tipos gerais de design experimental. Num deles, o between-subjects design, diferentes grupos de participantes podem contribuir com dados para diferentes situações da variável independente. Neste design, os participantes podem fazer parte de apenas uma das condições do experimento. Cada condição diferente do estudo envolve um grupo diferente de participantes. Este tipo de design é necessário quando as variáveis do sujeito estão sendo estudadas ou quando o fato 
de ele estar em uma condição do experimento muda os participantes de modo que torna impossível para ele fazer parte de outra condição, especialmente quando o conhecimento obtido ao participar numa etapa do processo alimenta o viés de conhecimento prévio na participação em outra etapa do mesmo. No outro tipo, within-subject design, os mesmos participantes contribuem com dados para todas as situações da variável independente. Cada indivíduo participa em todas as condições do estudo. A participação em uma condição pode afetar o modo como os participantes irão se comportar em outras condições (Goodwin, 2008).

A metodologia experimental de pesquisa busca principalmente, a validade interna. A generalização para demais contextos de análise não é uma exigência metodológica (Brewer \& Hunter, 2006).

Para a avaliação das relações entre as variáveis deste estudo, adotou-se a perspectiva sugerida por Hair et al. (2010), quanto à utilização de técnicas de análise multivariadas.

A ANOVA (Analysis of Variance) é uma das principais técnicas de análise empregadas na metodologia experimental. É uma técnica estatística utilizada para determinar se as amostras provenientes de dois ou mais grupos vêm de populações com médias iguais (Hair et al., 2010). A análise de variância compara a variabilidade nos escores (variância) entre os diferentes grupos com a variabilidade dentro de cada um dos grupos. A taxa de razão $\mathrm{F}$ indica a variação entre os grupos dividida pela a variação dentro dos grupos. Valores altos de $\mathrm{F}$ indicam que existe uma maior variabilidade entre os grupos - causada pela variável independente - do que existe no interior de cada grupo. Um teste $\mathrm{F}$ com resultado estatisticamente significativo, indica que as médias populacionais são diferentes (Pallant, 2011).

Nos experimentos 1 e 2 foram utilizadas a two-way ANOVA between-groups. O termo two-way refere-se à existência de duas variáveis independentes, e between-groups indica que diferentes indivíduos estão alocados em cada um dos grupos. Por ser uma técnica estatística paramétrica, assume-se que a população amostrada tenha uma distribuição normal. Deste modo, se cada grupo tiver ao menos 30 indivíduos, a técnica é robusta o suficiente para minimizar os efeitos de uma possível violação da normalidade (Pallant, 2011).

Outra técnica estatística empregada neste estudo foi a análise de regressão. A regressão múltipla compreende uma família de técnicas que podem ser utilizadas para explorar a relação entre uma variável dependente contínua e um número de variáveis independentes (ou preditores), geralmente contínuas. A regressão múltipla é baseada na correlação, mas permite uma exploração mais sofisticada da inter-relação entre um conjunto de variáveis (Pallant, 2011).

Em experimentos utilizando seres humanos, uma amostra de 15 indivíduos por grupo pode ser considerada suficiente, desde que o desvio padrão das amostras não seja muito diferente e que elas tenham distribuição simétrica. Entretanto, com 30 sujeitos em cada grupo não há necessidade de levar em consideração a distribuição da amostra, pois o teorema central do limite afirma que, quando o tamanho da amostra aumenta, a distribuição amostral da sua média tende a aproximar-se de uma distribuição normal (Mourão Júnior, 2009; James, 2004).

Deste modo, em um design experimental do tipo $3 \times 2$ são formados 6 grupos, sendo que a amostra necessária é de 180 participantes (experimento 1). Para um design do tipo $3 \times 2 \times 2$, existem 12 grupos e a amostra deve ser de 360 indivíduos (experimento 2).

As análises estatísticas deste trabalho foram realizadas com auxílio do pacote estatístico SPSS versão 17.

\section{Apresentação e Análise dos Dados}

\subsection{Procedimentos do Experimento 1}

O primeiro experimento teve o propósito de avaliar se os resultados anteriores de ganhos de ações de empresas afetavam a preferência dos consumidores pela compra ou venda destas ações. O objetivo foi verificar a ocorrência da falácia do jogador e do viés da mão quente. Foi utilizado um procedimento similar ao realizado por Johnson e Tellis (2005).

A amostra foi composta por 181 estudantes de graduação de uma universidade no Sul do Brasil, com idade média de 22,4 anos, sendo $47 \%$ do sexo feminino. Estes foram informados que receberiam créditos de atividades suplementares pela participação na pesquisa. Todos os participantes eram alunos do curso de Administração e tinham conhecimentos diferentes de finanças 
e mercado acionário em função do tempo de estudo. Alunos dos anos iniciais tinham menor conhecimento do que alunos concluintes. Os dados foram coletados entre os meses de março e abril de 2012. A amostra foi do tipo não probabilística, por conveniência e a participação foi voluntária. Uma das premissas do método experimental é a busca de validade interna. O fato do tipo de coleta de dados não permitir generalização externa não representa uma limitação que impeça as implicações teóricas deste trabalho.

O design deste estudo foi 3 (Tamanho da sequência de ganhos: 3, 7 ou 11 trimestres) x 2 (Tipo de negócio: compra ou venda de ações) between-subjects. O nível de significância $\alpha$ foi 0,05 , conforme prática na área de Ciências Sociais (Gaur \& Gaur, 2009, p.35).

Os respondentes foram alocados aleatoriamente a uma das seis condições, conforme indicado na Tabela 1. Quanto ao tamanho da amostra, procurou-se obter em torno de 30 casos em cada condição. Deste modo, foram formados grupos bastante homogêneos e muito próximos ou acima do mínimo recomendável para estudos paramétricos, assegurando o atendimento dos pressupostos estatísticos para as análises realizadas, especialmente com a utilização de testes estatísticos adequadamente robustos (Gaur \& Gaur, 2009; Hair et al., 2010).

Tendo em vista que este primeiro estudo é uma adaptação do estudo de Johnson e Tellis (2005), julgou-se que não havia a necessidade da realização de um pré-teste.

Tabela 1

Distribuição da Amostra no Experimento 1

\begin{tabular}{|l|c|c|c|c|}
\hline \multicolumn{1}{|c|}{ Condição } & $\mathbf{3}$ Trimestres & $\mathbf{7}$ Trimestres & $\mathbf{1 1}$ Trimestres & Total \\
\hline Compra de ações & 30 & 26 & 29 & 85 \\
\hline Venda de ações & 36 & 29 & 31 & 96 \\
\hline Total & 66 & 55 & 60 & 181 \\
\hline
\end{tabular}

Nota. Fonte: Coleta de dados do experimento 1.

Para a sequência de ganhos positivos, foi apresentada uma tabela com uma sequência crescente de ganhos positivos, ao passo que para os ganhos negativos, aparecia uma sequência decrescente de ganhos positivos. A escolha de ganhos positivos para os dois casos se deve ao fato de que em mercados reais, é difícil uma longa série de ganhos negativos. Além disso, os consumidores percebem uma sequência decrescente, mesmo com ganhos positivos, como um sinal negativo (Johnson \& Tellis, 2005).

Tabela 2

Exemplo da condição de compra com sequência de 7 trimestres de ganhos

Empresa Haloo:

\begin{tabular}{|l|c|c|c|c|c|c|c|}
\hline Ano & \multicolumn{3}{|c|}{2010} & \multicolumn{4}{|c|}{2011} \\
\hline Trimestre & T2 & T3 & T4 & T1 & T2 & T3 & T4 \\
\hline LPA (R\$) & 0,32 & 0,45 & 0,51 & 0,64 & 0,81 & 0,91 & 0,99 \\
\hline
\end{tabular}

Empresa Andaz:

\begin{tabular}{|l|c|c|c|c|c|c|c|}
\hline Ano & \multicolumn{3}{|c|}{2010} & \multicolumn{4}{|c|}{2011} \\
\hline Trimestre & T2 & T3 & T4 & T1 & T2 & T3 & T4 \\
\hline LPA (R\$) & 0,94 & 0,88 & 0,82 & 0,69 & 0,59 & 0,48 & 0,43 \\
\hline
\end{tabular}

Nota. LPA = lucro líquido por ação (por exemplo, se no trimestre você teve um LPA de 0,57, e você tem 100 ações, significa que seu lucro líquido foi de $\mathrm{R} \$ 57,00$ neste período)

Fonte: Adaptado de Johnson \& Tellis (2005).

Os participantes alocados na condição de compra recebiam uma ficha, contendo um texto que explicava um cenário de investimento. Este texto é reproduzido a seguir, na condição de 7 trimestres:

Você acabou de receber uma restituição do imposto de renda de $\mathrm{R} \$ 1.000,00$. Você pretende investir no mercado de ações por um curto período de tempo, apenas um trimestre. Você pede para que seu corretor Ihe recomende duas possibilidades de investimentos em ações, baseadas em certos critérios que você especificou. Ele Ihe apresenta ações de duas empresas, a Haloo e a Andaz, as quais satisfazem a maioria dos critérios que você havia estabelecido. Entretanto, elas diferem substancialmente, no quesito de ganhos recentes. A Haloo tem tido 7 trimestres de ganhos ascendentes, ao passo que a Andaz tem tido 7 trimestres de ganhos descendentes, conforme indicado a seguir. 
Após o texto, era apresentada uma tabela com a sequência de ganhos das empresas. Foram apresentadas três condições de tamanho da sequência de ganhos: 3, 7 e 11 trimestres, uma para cada subgrupo e todos deveriam indicar qual seria a empresa de sua escolha para a compra das ações. Na Tabela 2 é apresentado um exemplo com uma sequência de 7 trimestres, que foi utilizado tanto na condição de compra quanto na condição de venda.

Na condição de venda, os participantes recebiam uma ficha com um texto contendo um outro cenário de investimento. Este texto é reproduzido a seguir, na condição de 7 trimestres:

\begin{abstract}
Você acabou de herdar um portfólio em ações no valor de $\mathrm{R} \$ 2.000,00$. Você pretende comprar um computador no valor de $\mathrm{R} \$ 1.000,00$ e precisa vender algumas ações para isto. Você pede para que seu corretor the recomende duas opções entre o seu portfólio, baseadas em certos critérios que você especificou. Ele Ihe apresenta ações de duas empresas, a Haloo e a Andaz, as quais satisfazem a maioria dos critérios que você havia estabelecido. Entretanto, elas diferem substancialmente, no quesito de ganhos recentes. A Haloo tem tido 7 trimestres de ganhos ascendentes, ao passo que a Andaz tem tido 7 trimestres de ganhos descendentes, conforme indicado a seguir.
\end{abstract}

Após o texto, era apresentada a tabela com a sequência de ganhos das empresas (ver Tabela 2). Cada subgrupo recebia um tamanho de sequência diferente e tinha que indicar de qual maneira ele deveria vender as ações.

Depois da tabela, os participantes respondiam algumas questões. Uma delas avaliava a preferência dos respondentes pelas ações das duas empresas (ganhos positivos ascendentes versus descendentes) por meio de uma escala de 5 pontos: (1) Com certeza a Andaz; (2) Talvez a Andaz; (3) Indiferente; (4) Talvez a Haloo; (5) Com certeza a Haloo. Os participantes também indicavam como iriam investir (comprar) ou resgatar (vender) as ações: (1) $100 \%$ Haloo; (2) $75 \%$ Haloo $+25 \%$ Andaz; (3) $50 \%$ Haloo + 50\% Andaz; (4) $25 \%$ Haloo + 75\% Andaz; (5) $100 \%$ Andaz. Outras duas questões de controle indicavam o grau de conhecimento e de experiência com o mercado de ações de um modo geral, também utilizando uma escala de 5 pontos: (1) Muito baixo; (2) Baixo; (3) Moderado; (4) Alto; (5) Muito alto.

\title{
4.2 Resultados do Experimento 1
}

Para testar as hipóteses sobre a falácia do jogador e a teoria da mão quente, foi rodada uma análise de regressão múltipla, com termos lineares e quadráticos. A variável dependente é a intenção de compra ou venda da Haloo (empresa com sequência de ganhos crescentes), representada pelo percentual de investimento (situação de compra) ou resgate (situação de venda) de ações da referida empresa. Os termos da equação são:

Intenção de compra/venda da Haloo $=$ Intercept $+\beta_{1}$ (Compra $x$ Tamanho da sequência) $+\beta_{2}$ (Compra $x$ Tamanho da sequência $\left.{ }^{2}\right)+\beta_{3}($ Venda $\times$ Tamanho da sequência $)+\beta_{4}\left(\right.$ Venda $\times$ Tamanho da sequência $\left.{ }^{2}\right)+\varepsilon$

Os resultados da regressão com a amostra total indicaram que não foram obtidas relações significativas entre a variável dependente e os preditores, contrariando a expectativa inicial. Desta forma, a hipótese $\mathrm{H} 1$ foi rejeitada, ou seja, a intenção de compra ou venda de ações não variou em função do tamanho da sequência de ganhos positivos. Nova análise de regressão múltipla foi executada, desta vez separando-se a amostra por gênero. Os resultados da análise contemplando apenas a amostra feminina foram análogos ao da amostra total. Por outro lado, os resultados da análise de regressão utilizando apenas a amostra masculina foram significativos (ver Tabela 3), observando-se a ocorrência da falácia do jogador somente com consumidores do sexo masculino, aceitando a hipótese $\mathrm{H} 2$.

Tabela 3

Regressão Entre Intenção de Compra/Venda da Haloo e Tamanho da Sequência de Ganhos Amostra Masculina

\begin{tabular}{|l|c|c|c|}
\hline \multicolumn{1}{|c|}{ Variável } & Beta & t & Sig. \\
\hline Constante & & 4,851 & 0,000 \\
\hline Compra x Tamanho da sequência & $-2,750$ & $-2,622$ & 0,010 \\
\hline Compra x Tamanho da sequência ${ }^{2}$ & 2,105 & 2,742 & 0,007 \\
\hline Venda X Tamanho da sequência & $-2,308$ & $-2,220$ & 0,029 \\
\hline Venda X Tamanho da sequência ${ }^{2}$ & 1,448 & 1,887 & 0,062 \\
\hline
\end{tabular}

Nota. $R^{2}=0,108 ; F=2,747(p=0,033) ; N=96$. Fonte: Coleta de dados do experimento 1. 
Conforme pode ser observado pelo coeficiente negativo e significativo Compra $x$ Tamanho da sequência $(\beta=-2,750, p=0,010)$, para uma sequência de ganhos crescentes, a intenção de compra de ações da Haloo pelos consumidores diminui conforme aumenta o número de trimestres da sequência de ganhos apresentada. Após um determinado ponto crítico, há uma inversão desta intenção de compra, indicado pelo coeficiente positivo e significativo ao nível de $p<0,05$ Compra $x$ Tamanho da sequência ${ }^{2}(\beta=2,105, p=0,007)$. Em resumo, para os consumidores masculinos, sua intenção de compra de ações da Haloo começa em um nível alto ( 3 trimestres), depois diminui ( 7 trimestres), voltando a aumentar (11 trimestres). A intenção de venda da Haloo segue uma tendência análoga à condição de compra (Venda x Tamanho da sequência: $\beta=-2,308, p=0,029$ ). Entretanto, após um determinado ponto crítico (Venda $x$ Tamanho da sequência ${ }^{2}: \beta=1,448, p=$ $0,062)$, a intenção de venda deixa de diminuir e estabiliza-se. Os resultados podem ser visualizados na Figura 1.

\section{Intenção de compra/venda da Haloo - ganhos crescentes}

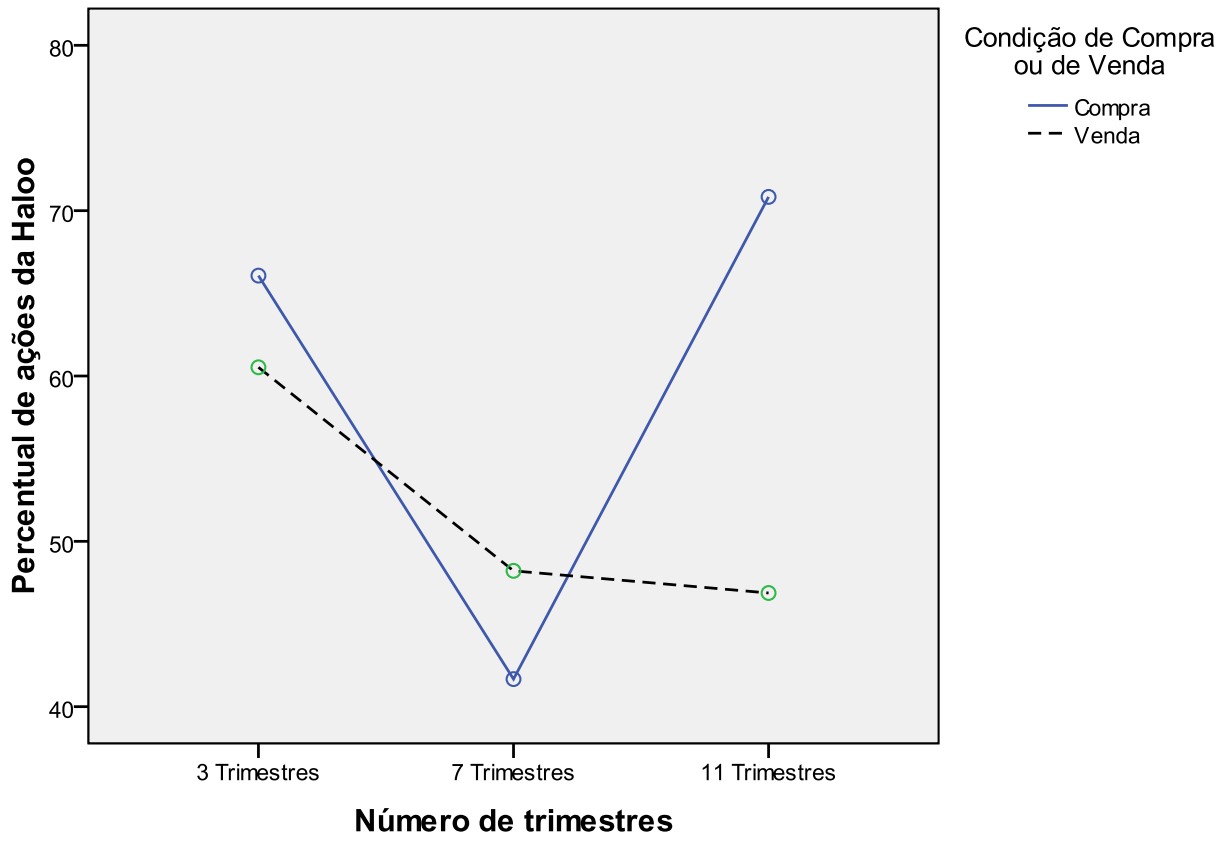

Figura 1 - Intenção de compra/venda da Haloo (ganhos crescentes) - amostra masculina Nota. Fonte: Coleta de dados do experimento 1.

Para permitir a avaliação simultânea de duas variáveis independentes, uma análise de two-way ANOVA foi realizada para avaliar as diferenças nas intenções de compra/venda da empresa Haloo em função do gênero. A amostra foi dividia em três grupos de acordo com o tamanho da sequência de ganhos (1, 2 e 3 trimestres). Considerando-se apenas a condição de compra, foi encontrado um efeito principal estatisticamente significativo ao nível de $p<0,05$ para o tamanho da sequência ( $F(2$, $79)=5,61, p=0,005)$. O tamanho do efeito, calculado por meio do partial eta squared, foi de 0,124 , valor considerado grande (ver Pallant, 2011). Comparações post-hoc usando o teste Tuckey HSD indicaram diferença estatisticamente significativa entre 3 e 11 trimestres e entre 7 e 11 trimestres. Não houve efeito principal para gênero $(F(2,79)=0,205, p=0,652)$, mas foi constatado efeito de interação entre tamanho da sequência e gênero $(F(2,79)=4,05, p=0,021)$. O tamanho do efeito, calculado por meio do partial eta squared, foi de 0,093, valor considerado entre médio e grande (ver Pallant, 2011). Na condição de venda não foram encontradas diferenças significativas. Os resultados podem ser visualizados na Figura 2. Isto indica que a intenção de compra dos homens é afetada pelo histórico de ganhos, o que não ocorre com as mulheres. 


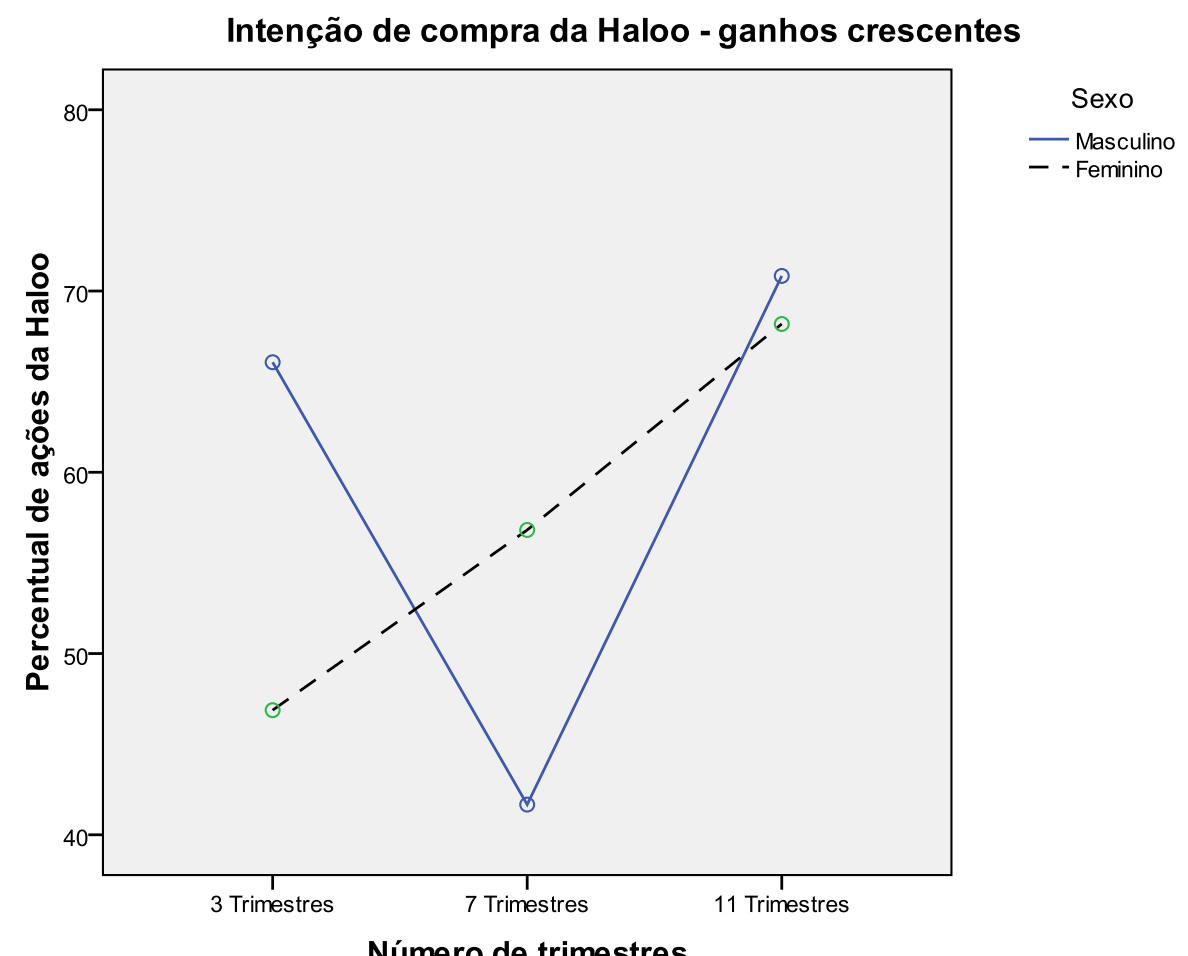

Figura 2 - Intenção de compra da Haloo (ganhos crescentes) em função do gênero Nota. Fonte: Coleta de dados do experimento 1.

\subsection{Procedimentos do Experimento 2 - Autorregulação X Falácia do Jogador e Teoria da Mão Quente}

O estudo seguinte foi realizado com o intuito de verificar o papel da autorregulação no viés da falácia do jogador e da teoria da mão quente. O experimento 2 foi composto por duas partes. Na primeira etapa, o pesquisado respondia algumas questões, que tinham por objetivo a indução para o foco regulatório, ou seja, fazê-lo entrar em promoção ou prevenção, de acordo com a pesquisa que recebia (distribuída de modo aleatório). A segunda parte foi idêntica ao experimento 1.

A amostra foi composta por 389 estudantes de graduação recrutados de universidades do Sul do Brasil, com idade média de 22,3 anos, sendo $48,8 \%$ do sexo feminino. Estes foram informados que receberiam créditos de atividades suplementares pela participação na pesquisa. Todos os participantes eram alunos do curso de Administração e tinham conhecimentos diferentes de finanças e mercado acionário em função do tempo de estudo. Alunos dos anos iniciais tinham menor conhecimento do que alunos concluintes. Os dados foram coletados entre os meses de junho e setembro de 2012.

Este segundo experimento foi do tipo 3 (Tamanho da sequência de ganhos: 3, 7 ou 11 trimestres) $\times 2$ (Tipo de negócio: compra ou venda de ações) x 2 (Autorregulação: promoção ou prevenção) between-subjects design. Os respondentes foram alocados aleatoriamente a uma das doze condições.

Seguindo os mesmos critérios do primeiro experimento quanto ao tamanho da amostra, procurou-se obter em torno de 30 casos em cada grupo. Tendo em vista que o número de condições passou de 6 para 12, o número da amostra dobrou em relação ao estudo anterior.

Os participantes foram informados oralmente e por escrito (na primeira página) que se tratava de duas pesquisas, a primeira na área de psicologia e a segunda sobre investimentos. Para realizar a indução para o foco regulatório, a primeira etapa apresentava uma tarefa não relacionada, com o propósito de avaliar se a capacidade de definir claramente objetivos e estratégias pessoais (ver Higgins et al., 1994) ajudava a resolver problemas simples. Em uma das tarefas, foi apresentado um labirinto, recurso que também foi utilizado em outros estudos, tais como Friedman \& Förster (2001), Gonçalves (2009) e Viacava (2012).

Os respondentes foram instruídos a escrever até 5 objetivos - principais esperanças e aspirações envolvendo o futuro acadêmico e/ou profissional - e pelo menos 5 estratégias - coisas 
que ele deveria alcançar que Ihe ajudariam a realizar seus objetivos acadêmicos e profissionais. Foi oferecido um início de frase de acordo com o foco regulatório em questão. Para o foco em promoção, metade das frases iniciavam com "eu devo alcançar" e a outra metade, com "eu devo conseguir". De modo similar, no foco em prevenção, metade das frases iniciavam com "eu devo me afastar", e a outra metade com "eu devo evitar". Na folha seguinte, era apresentado um labirinto, o qual continha um objetivo de acordo com o foco regulatório: "Ajude o rato a sair do labirinto e comer o queijo" (foco em promoção) ou "Ajude o rato a sair do labirinto e fugir da coruja" (foco em prevenção). A verificação da indução do foco regulatório foi feita por meio das análises das respostas sobre os objetivos e estratégias, em que foram selecionados apenas os casos que cumpriram de modo satisfatório todas as tarefas solicitadas.

Em seguida, os participantes foram solicitados a responder a pesquisa sobre investimento - a mesma utilizada no estudo 1. Eles não foram informados de que existiam condições diferentes com o propósito de não afetar o resultado do experimento.

Seguindo a recomendação de Goodwin (2008), na última etapa da pesquisa foi realizado um debriefing, que é "o processo de informar aos participantes da pesquisa sobre o estudo depois que ele termina" (Shadish et al., 2002, p.506). Este procedimento é importante, pois ajuda a identificar possíveis falhas da pesquisa e tirar dúvidas sobre o experimento. Os participantes também foram questionados sobre o envolvimento deles durante a pesquisa, além de determinar se eles conseguiram adivinhar a real relação entre as etapas 1 e 2 . Dois respondentes foram excluídos da amostra final por terem acertado esta relação.

\subsection{Resultados do Experimento 2}

Inicialmente, foi realizada uma comparação das médias da intenção de compra e venda dos participantes com foco em promoção e prevenção. Deste modo, uma análise de two-way ANOVA foi efetuada para avaliar as diferenças nas intenções de compra/venda da Haloo em função do foco da autorregulação. $\mathrm{Na}$ condição de compra foi encontrado um efeito principal significativo ao nível de $p$ $<0,05$ para o tamanho da sequência $(F(2,189)=3,56, p=0,030)$. O tamanho do efeito, calculado por meio do partial eta squared, foi de 0,036, valor considerado entre pequeno e médio (ver Pallant, 2011). Comparações post-hoc usando o teste Tuckey HSD indicaram uma diferença marginalmente significativa $(p=0,060)$ entre os grupos com sequências de 3 e 7 trimestres. Não houve efeito principal para autorregulação $(F(1,189)=0,02, p=0,885)$, e também não foi constatado efeito de interação entre tamanho da sequência e autorregulação $(F(2,189)=1,07, p=0,346)$. Na condição de venda não foram encontradas diferenças significativas (autorregulação: $F(1,188)=0,09, p=$ 0,769). A partir destes resultados, optou-se por fazer a análise juntando os focos de promoção e prevenção, representados agora como condição de autorregulação.

Para testar a hipótese sobre a influência da autorregulação nas falácias do jogador e da mão quente, foram realizadas análises de regressão múltipla. Os resultados são mostrados na Tabela 4.

Tabela 4

Regressão Entre Intenção de Compra/Venda da Haloo e Tamanho da Sequência de Ganhos - Com Autorregulação

\begin{tabular}{|l|c|c|c|}
\hline \multicolumn{1}{|c|}{ Variável } & Beta & t & Sig. \\
\hline Constante & & 2,642 & 0,009 \\
\hline Compra x Tamanho da sequência & 1,550 & 3,406 & 0,001 \\
\hline Compra x Tamanho da sequência ${ }^{2}$ & $-0,964$ & $-2,845$ & 0,005 \\
\hline Venda X Tamanho da sequência $^{2}$ & 1,544 & 3,543 & 0,000 \\
\hline Venda X Tamanho da sequência ${ }^{2}$ & $-1,108$ & $-3,482$ & 0,001 \\
\hline
\end{tabular}

Nota. $R^{2}=0,053 ; F=5,310(p=0,000) ; N=389$. Fonte: Coleta de dados do experimento 2.

A hipótese H3 propõe que, para consumidores com indução de foco regulatório, uma sequência de ganhos crescentes faz com que a intenção de compra de ações aumente conforme cresça o número de trimestres da sequência de ganhos apresentada. Depois de um determinado ponto crítico, a intenção de compra para de aumentar e estabiliza-se. Os resultados indicados na Tabela 4 mostram uma inversão nos sinais dos betas em relação ao experimento 1 (amostra masculina). Isto significa que para uma sequência de ganhos crescentes, a intenção de compra de ações da Haloo pelos consumidores aumenta conforme aumenta o número de trimestres da sequência de ganhos apresentada (Compra $x$ Tamanho da sequência: $\beta=1,550, p=0,001$ ). Depois de um determinado ponto crítico (Compra $x$ Tamanho da sequência': $\beta=-0,964, p=0,005$ ), a intenção de compra para 
de aumentar e estabiliza-se. Em outras palavras, a intenção de compra de ações da Haloo pelos consumidores começa em um nível baixo ( 3 trimestres), depois aumenta ( 7 trimestres) e finalmente estabiliza-se (11 trimestres). Estes resultados aceitam parcialmente H3, na condição de compra.

A intenção de venda da Haloo segue uma tendência análoga à condição de compra, incrementando conforme aumenta o tamanho da sequência (Venda x Tamanho da sequência: $\beta=$ $1,544, p=0,000)$. Entretanto, após um determinado ponto crítico, há uma inversão desta intenção de venda (Venda $\times$ Tamanho da sequência $: \beta=-1,108, p=0,001$ ), a qual passa a diminuir. Estes resultados rejeitam parcialmente $\mathrm{H3}$ na condição de venda, na qual esperava-se que a intenção de venda das ações diminuiria num primeiro momento e depois ficaria estável.

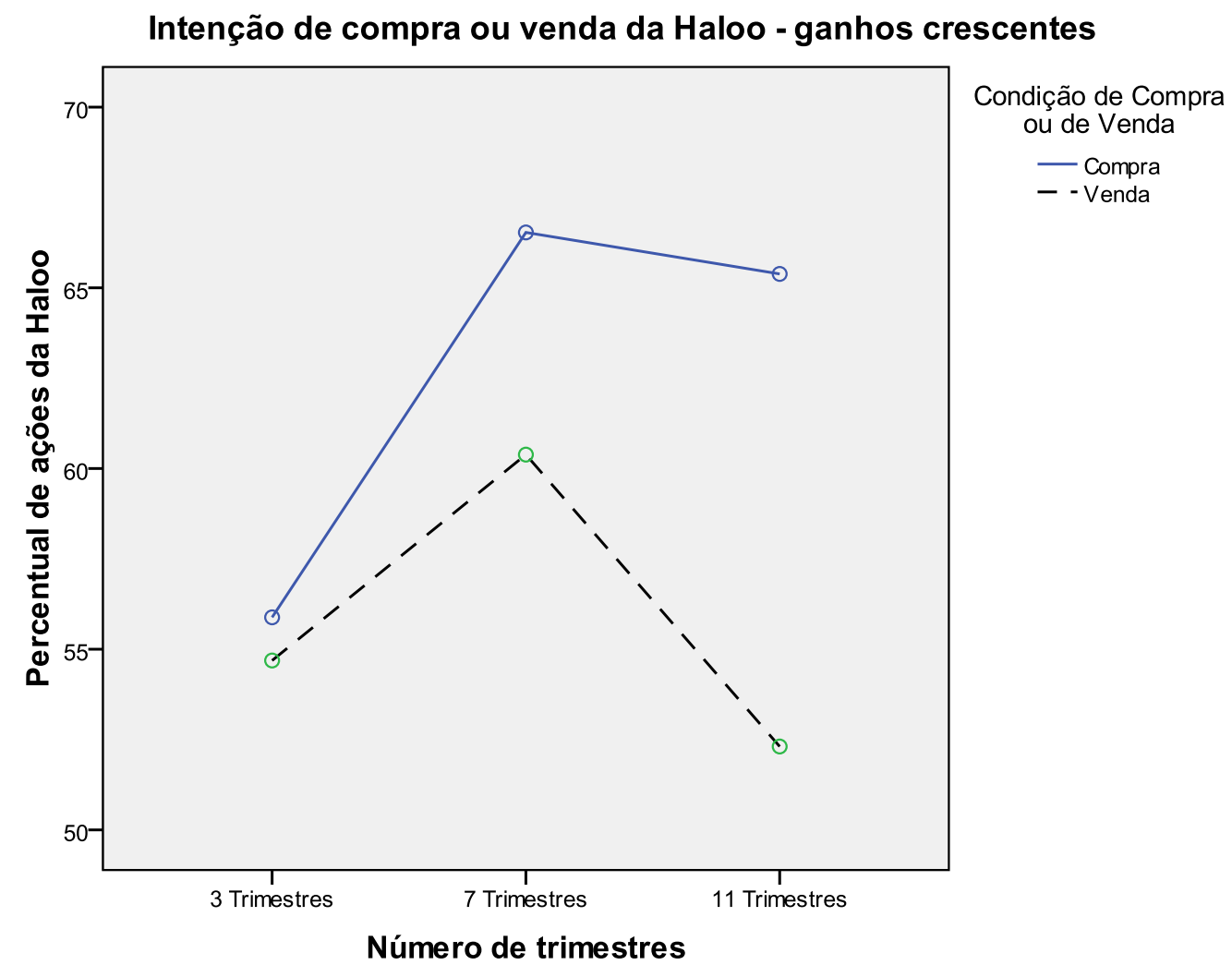

Figura 3 - Intenção de compra/venda da Haloo (ganhos crescentes) - com autorregulação Nota. Fonte: Coleta de dados do experimento 2.

Foi realizada uma comparação entre os resultados dos experimentos 1 e 2. Para tanto, foi efetuada uma análise de two-way ANOVA para avaliar as diferenças nas intenções de compra/venda da Haloo em função do estímulo (com e sem autorregulação). Na condição de compra foi encontrado um efeito principal significativo ao nível de $p<0,05$ para o tamanho da sequência $(F(2,274)=5,05$, $p=0,007)$. O tamanho do efeito, calculado por meio do partial eta squared, foi de 0,036, valor considerado entre pequeno e médio (ver Pallant, 2011). Comparações post-hoc usando o teste Tuckey HSD indicaram uma diferença estatisticamente significativa $(p=0,009)$ entre os grupos com sequências de 3 e 11 trimestres. Não houve efeito principal para o estímulo de autorregulação $(F(1$, $274)=1,99, p=0,159)$. Foi constatado efeito de interação ao nível de $p<0,05$ entre tamanho da sequência e estímulo de autorregulação $(F(2,274)=4,28, p=0,015)$. O tamanho do efeito, calculado por meio do partial eta squared, foi de 0,030 , valor considerado entre pequeno e médio (ver Pallant, 2011). Na condição de venda não foram encontradas diferenças significativas (estímulo de autorregulação: $F(1,284)=2,03, p=0,156)$. 


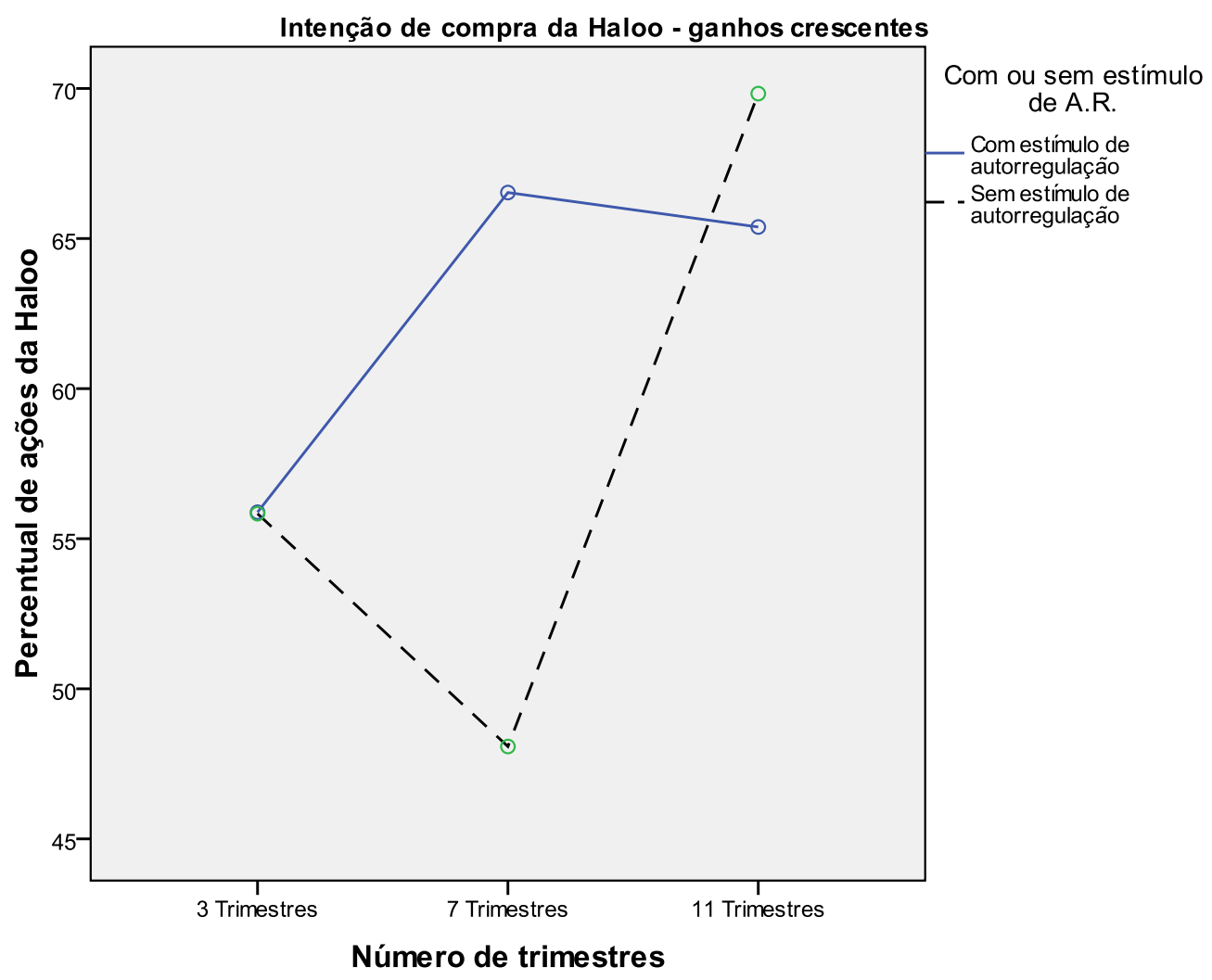

Figura 4 - Intenção de compra da Haloo (ganhos crescentes) - com e sem autorregulação Nota. Fonte: Coleta de dados do experimento 2.

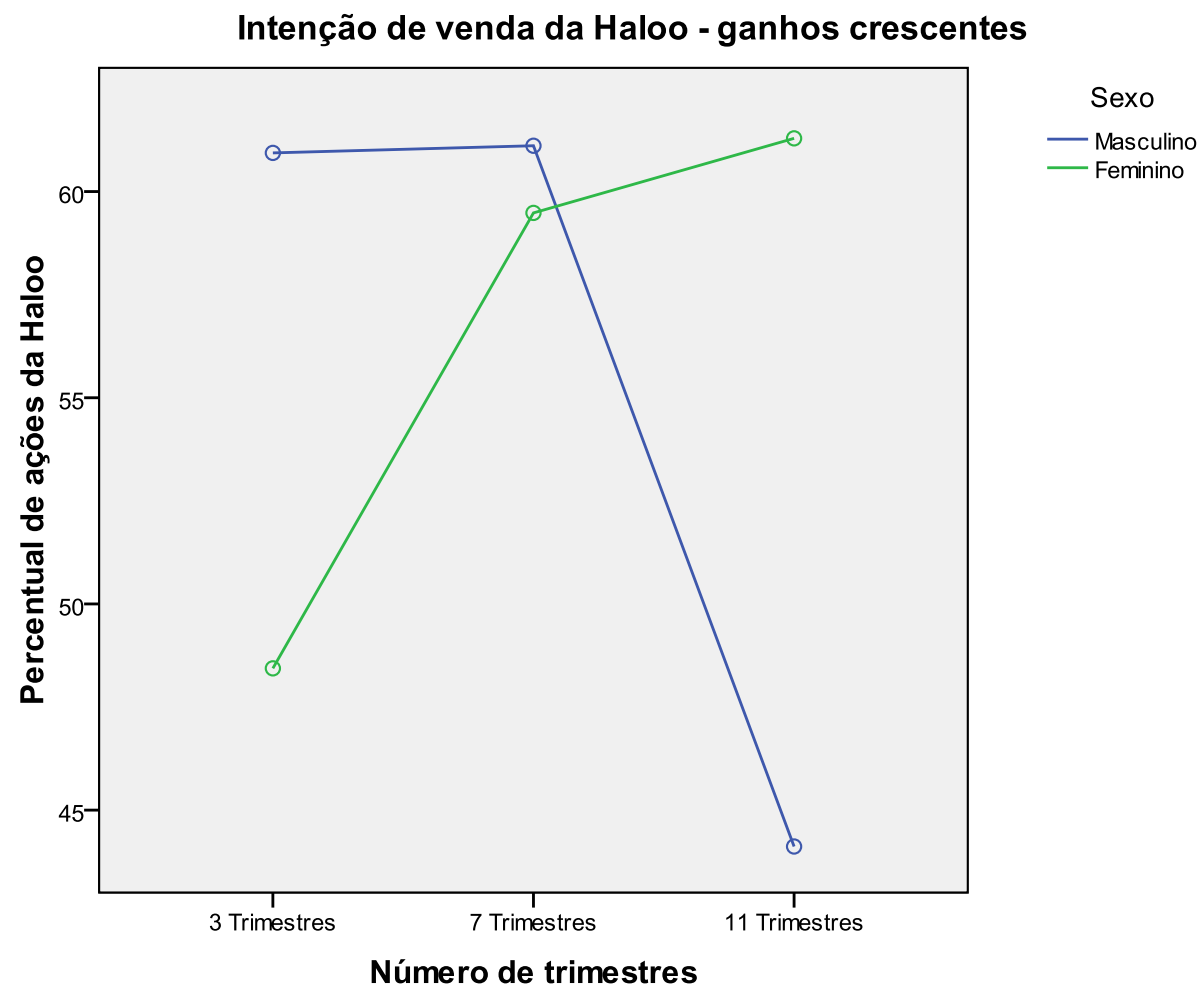

Figura 5 - Intenção de venda da Haloo (ganhos crescentes) em função do gênero Nota. Fonte: Coleta de dados do experimento 2. 
Também foi avaliada a diferença das intenções de compra e venda das ações em função do gênero por meio de uma análise de two-way ANOVA. Na condição de compra não foi encontrado efeito principal para gênero $(F(1,189)=1,301, p=0,255)$. Também não houve efeito de interação. $\mathrm{Na}$ condição de venda, não foram encontrados efeitos principais. Entretanto, foi observado um efeito de interação ao nível de $p<0,05$ entre o tamanho da sequência e o gênero $(F(2,188)=3,68, p=$ 0,027). O tamanho do efeito, calculado por meio do partial eta squared, foi de 0,038 , valor considerado entre pequeno e médio (ver Pallant, 2011). Isto significa que os homens, em relação às mulheres, apresentam uma menor intenção de venda de ações quando o número de trimestres com ganhos crescentes é maior, caracterizando a falácia do jogador.

\subsection{Discussão dos Resultados}

No primeiro experimento, os resultados obtidos com a amostra total refutaram a hipótese $\mathrm{H} 1$, ou seja, diante de resultados com uma sequência de ganhos positivos para uma ação, a preferência dos consumidores para a compra ou venda da ação não foi influenciada pelo tamanho daquela sequência. Deste modo, observou-se que não ocorreram os efeitos da falácia do jogador nem da mão quente. No entanto, refazendo-se a mesma análise separada por gênero, constatou-se que com as mulheres, a intenção de compra/venda das ações da Haloo (ganhos ascendentes) não foram afetadas pelo tamanho da sequência de eventos (número de trimestres). Deste modo, as mulheres não foram influenciadas pela falácia do jogador. Este resultado é coerente com o estudo de Suetens e Tyran (2012), no qual as mulheres, ao contrário dos homens, não foram influenciadas pela falácia do jogador em jogos da loteria estadual da Dinamarca. Por outro lado, com os consumidores masculinos, a intenção de compra de ações da Haloo começou em um nível alto, depois diminuiu, voltando a aumentar. Com isto, conforme esperado, constatou-se a ocorrência da falácia do jogador apenas para a amostra masculina, aceitando a hipótese H2 (Gilovich et al., 1985; Loh \& Warachka, 2012; Tversky \& Kahneman, 1971). Esta constatação reforça a ideia de que existem diferenças de gênero nas preferências de riscos, em que as mulheres são mais avessas ao risco e à competição do que os homens (Croson \& Gneezy, 2009). Entretanto, estes resultados são opostos ao encontrados no estudo de Johnson e Tellis (2005), conforme indicado pela hipótese H1 (no estudo destes autores não foi encontrada diferença entre os gêneros). Uma possível explicação poderia ser o fato de que parte da amostra pesquisada indicou possuir baixa experiência com o mercado de ações, em que $81,2 \%$ dos participantes do experimento 1 relataram experiência entre muito baixa e baixa, sem diferença entre gênero. Outra possibilidade seriam eventuais diferenças culturais entre norte americanos e brasileiros no que diz respeito ao modo como investem suas economias, bem como suas atitudes perante o risco.

O nível de conhecimento do mercado de ações relatado pelos pesquisados do experimento 1 foi mais elevado do que a experiência no mercado de ações, sendo que apenas 48,6\% relataram conhecimento entre muito baixo e baixo. Por meio de uma análise de Qui-Quadrado para fazer a comparação entre médias, observou-se uma diferença ao nível de $p<0,05$ entre os gêneros $(\chi 2)$ ( 3 , $\mathrm{N}=181$ ) $=10,30, \mathrm{p}=0,016$ ), em que os homens indicaram maior conhecimento do mercado de ações do que as mulheres. É possível que esta diferença ajude a explicar o motivo da amostra feminina não ter sido influenciada pela falácia do jogador no contexto estudado.

Na condição de venda, na amostra masculina foi observado o efeito da falácia do jogador para uma sequência pequena de eventos (entre 3 e 7 trimestres), ou seja, existe a crença de que os resultados da sequência de ganhos será alterada em breve, afetando a intenção de venda das ações (Kahneman \& Tversky, 1972; Lyons et al., 2013). Conforme aumentou-se o tamanho da sequência (entre 7 e 11 trimestres), constatou-se que o nível de intenção de venda não foi alterado. Isto caracteriza a ocorrência da falácia da mão quente, ou seja, a pessoa acredita que o resultado será mantido ao longo do tempo (Crosson \& Sundali, 2005; Gilovich et al., 1985).

A influência do foco regulatório no processo de decisão foi avaliada no segundo estudo. Apesar de cada pessoa carregar um determinado foco regulatório (Higgins, 1997), esse foco pode ser manipulado (Freitas et al., 2002). Esperava-se que a indução de um foco em promoção ou prevenção afetaria a atitude do sujeito perante o risco na tomada de decisão (Freitas \& Higgins, 2002). Os resultados indicaram que, após a indução de autorregulação, a intenção de compra de ações da Haloo pelos consumidores começa em um nível baixo, depois aumenta e finalmente estabiliza-se. Isto significa que para uma pequena sequência de resultados (número de trimestres), observa-se a ocorrência da falácia do jogador, na qual ocorre uma mudança na intenção de compra. Conforme o tamanho dessa sequência é aumentado, há uma tendência à manutenção da intenção de compra, caracterizando-se a falácia da mão quente. Na condição de compra, estes resultados aceitam 
parcialmente, a hipótese H3. Entretanto, na situação de venda era esperado um efeito contrário, o que não ocorreu, refutando em parte, H3.

Comparando-se os resultados com e sem estímulo de autorregulação, foi observado um efeito de interação entre tamanho da sequência e estímulo $(F(2,274)=4,28, p=0,015)$. Desse modo, constatou-se que há uma influência da autorregulação no processo decisório, quando o sujeito estimulado passou a ter uma intenção de compra significativamente maior da empresa com ganhos ascendentes na sequência com 7 trimestres. Por outro lado, na condição de venda, não foram encontradas diferenças significativas. Estes resultados são coerentes com a perspectiva de que a autorregulação afeta as estratégias que um sujeito usa para atingir uma determinada meta, neste caso representada pela busca da obtenção do melhor resultado financeiro possível (Higgins et al., 1994; Crowe \& Higgins, 1997; Shah, et al., 1998). Além disso, é interessante destacar que os sistemas motivacionais são flexíveis. Indivíduos com foco em promoção não estão sempre a procura de risco de forma rígida. Eles podem adaptar suas táticas de comportamento com o propósito de sustentar preocupações estratégicas fundamentais (Xi et al., 2014).

A análise das intenções de compra e venda das ações, em função do gênero, indicaram que na condição de venda foi observado um efeito de interação entre o tamanho da sequência e o gênero, evidenciando a diferença entre homens e mulheres em sua atitude perante uma tomada de decisão que envolve risco financeiro (Croson \& Gneezy, 2009). Os homens, mais do que as mulheres, apresentam uma menor intenção de venda de ações quando o número de trimestres com ganhos crescentes é maior. Isto caracteriza a falácia do jogador, ou seja, indivíduo julga que o próximo resultado deverá ser contrário ao obtido anteriormente (Gilovich et al., 1985; Loh \& Warachka, 2012; Tversky \& Kahneman, 1971).

\section{Conclusões e Recomendações}

Se toda tomada de decisão fosse inteiramente racional, seria esperado que os níveis de intenção de compra/venda seriam os mesmos, independente do tamanho da sequência ou de estímulos de autorregulação. Entretanto, os resultados encontrados demonstram que as pessoas, de um modo geral, atribuem significado a eventos que deveriam ser tratados como aleatórios. Isto levou os respondentes a fazerem escolhas enviesadas, as quais variaram em função do tamanho (número de trimestres) de uma sequência de ganhos positivos ascendentes e descendentes das ações de empresas fictícias. Dependendo da condição do estudo, observou-se a ocorrência da falácia do jogador - tendência de mudar o comportamento em função da sequência de eventos anteriores, acreditando que haverá uma inversão dos resultados (Gilovich et al., 1985; Loh \& Warachka, 2012; Tversky \& Kahneman, 1971) - e do viés da mão quente - tendência de manter o comportamento em função da sequência de eventos anteriores, acreditando que haverá uma manutenção dos resultados (Crosson \& Sundali, 2005; Gilovich et al., 1985).

Este trabalho diferencia-se dos demais estudos realizados sobre falácia do jogador e a teoria da mão quente, ao avaliar a influência da autorregulação afetiva nestes vieses. A partir da teoria do foco regulatório, acreditava-se que um sujeito com foco em promoção ou prevenção utilizaria estratégias mentais distintas para buscar um determinado resultado (Crowe \& Higgins, 1997; Higgins et al., 1994; Shah et al., 1998; Silva, 2011), o que poderia influenciar os vieses e heurísticas utilizados em suas tomadas de decisão. Deste modo, a principal contribuição deste trabalho é a descoberta de que a autorregulação afetiva teve um efeito de interação entre tamanho da sequência e estímulo na condição de compra. Isto representa uma alteração no comportamento da tomada de decisão, indicando claramente, uma mudança de viés da falácia do jogador (sem estímulo de autorregulação) para o viés da falácia da mão quente (com estímulo de autorregulação), conforme o aumento do tamanho da sequência de ganhos das ações (ver figura 4). Além disso, enfatiza-se que há influência do estado afetivo nas tomadas de decisão.

Outra contribuição importante desta pesquisa foram as diferenças entre gênero encontradas. Tal fato ficou evidente no primeiro estudo, no qual somente a amostra masculina apresentou o viés da falácia do jogador, ou seja, a intenção de compra foi afetada pelo histórico de ganhos das ações. No segundo estudo, novamente, foi constatado que a amostra feminina não apresentou o viés da falácia do jogador, efeito observado apenas entre os homens. Este achados corroboram estudos anteriores na área de economia (ver Croson \& Gneezy, 2009; Suetens \& Tyran, 2012) que relatam que as mulheres - em relação aos homens - apresentam diferenças nas preferências que envolvem risco e são menos suscetíveis à falácia do jogador. 
Os resultados encontrados neste estudo podem auxiliar instituições financeiras a fazerem uma melhor divulgação de seus produtos quando há o envolvimento de sequências de resultados anteriores. Índices financeiros como taxas de juros, cotação de moeda estrangeira e inflação podem mudar as decisões de compra, dependendo da maneira como tais indicadores são apresentados aos consumidores. Além disso, pequenos estímulos de autorregulação podem afetar drasticamente a tomada de decisão, podendo inverter a intenção de compra de um produto em uma determinada situação.

Entre as limitações deste estudo, pode-se citar que a amostra utilizada foi composta apenas por estudantes universitários, sendo que muitos indicaram baixa experiência e conhecimento do mercado de ações. Isto pode ter causado a inversão de alguns dos resultados esperados, refutando as duas primeiras hipóteses, as quais foram baseadas no experimento 1 de Johnson e Tellis (2005). Outra limitação foi a manipulação do foco regulatório, na qual não foi possível estabelecer uma distinção entre promoção e prevenção, fazendo com que a análise fosse realizada apenas em função da ausência (experimento 1) ou presença (experimento 2) do estímulo de autorregulação.

Futuros estudos poderiam ser realizados com o objetivo de explorar com maior profundidade as diferenças entre gênero encontradas neste estudo, tendo em vista que há poucos estudos na literatura que avaliam a influência do gênero nos vieses e heurísticas utilizados no processo de tomada de decisão.

\section{Notas}

1. Os autores deste artigo agradecem as valiosas recomendações dos avaliadores, as quais efetivamente contribuíram para a expansão e o desenvolvimento das ideias deste trabalho.

2. O autor Fábio P. Pádua Jr., recebi bolsa Capes/Reuni durante a realização deste artigo.

\section{Referências}

Aaker, J. L., \& Lee, A. (2001). “I" Seek Pleasures and "We” Avoid Pains: The Role of Self-regulatory Goals in Information Processing and Persuasion. Journal of Consumer Research, 28(June), 33-49.

Arkes, J., \& Martinez, J. (2011). Finally, evidence for a momentum effect in the NBA. Journal of Quantitative Analysis in Sports, 7(3).

Bonassi, F. V., Stern, R. B., \& Wechsler, S. (2008). The Gambler's Fallacy: A Bayesian Approach. AIP Conference Proceedings. Melville: American Institute of Physics, v.1073, 8-15.

Bower, B. (2010). Gambling on experience: Perceptions of risk can get pulled in opposite directions. Science News, 177(9), 26-29.

Brewer, J., \& Hunter, A. (2006). Foundations of multimethod research: synthesizing styles. Thousand Oaks: Sage Publications.

Clotfelter, C. T., \& Cook, P. J. (1993). The "Gamblers Fallacy" in Lottery Play. Management Science, 39(12), 1521-1525.

Croson, R., \& Gneezy, U. (2009). Gender Differences in Preferences. Journal of Economic Literature, 47(2), 1-27.

Crosson, R., \& Sundali, J. (2005). The Gambler's Fallacy and the Hot Hand: Empirical Data from Casinos. The Journal of Risk and Uncertainty, 30(3), 195-209.

Crowe, E., \& Higgins, E. T. (1997). Regulatory Focus and Strategic Inclinations: Promotion and Prevention in Decision-Making. Organizational Behavior and Human Decision Processes, 69(February), 117-132.

Dong G., Lin X., Zhou H., \& Du X. (2014). Decision-making after continuous wins or losses in a randomized guessing task: implications for how the prior selection results affect subsequent decision-making. Behavioral And Brain Functions, 10, 1-11.

Fishbach, A., \& Ferguson, M. (2007). The Goal Construct in Social Psychology. Invited Chapter In A. W. Kruglanski \& E. T. Higgins (Eds.), Social Psychology: Handbook of Basic Principles. (Vol. II, pp. 490-515). New York: Guilford Press. 
Freitas, A. L., \& Higgins, E. T. (2002). Enjoying Goal-Directed Action: The Role of Regulatory Fit. Psychological Science, 13(January), 1-6.

Freitas, A. L., Liberman, N., \& Higgins, E. T. (2002). Regulatory Fit and Resisting Temptation during Goal Pursuit. Journal of Experimental Social Psychology, 38, 291-298.

Friedman, R., \& Förster, J. (2001). The Effects of Promotion and Prevention Cues on Creativity. Journal of Personality and Social Psychology, 81, 1001-1013.

Gaur, A. S., \& Gaur, S. S. (2009). Statistical Methods for Practice and Research: A guide to data analysis using SPSS. ( $2^{\text {nd }}$ ed.). Thousand Oaks: SAGE Publications Ltd.

Gilovich, T., Vallone R., \& Tversky, A. (1985). The Hot Hand in Basketball: On the Misperception of Random Sequences. Cognitive Psychology, 17, 295-314.

Gonçalves, M. A. (2009). Quando o Dinheiro Compra Mais Felicidade? O Papel da Self-Regulation na Felicidade de Consumidores com Experiências e Bens Materiais. Dissertação de mestrado, Universidade Federal do Rio Grande do Sul, Porto Alegre, RS, Brasil.

Goodwin, C. J. (2008). Research in Psychology: Methods and Design. (5. ed.). New York: Wiley. Goodwin, P., \& Wright, G. (2000). Decision Analysis for Management Judgment. (2. ed.). New York: Wiley.

Hair, J. F. Jr., Black, W. C., Babin, B. J., \& Anderson, R. E. (2010). Multivariate Data Analysis. (7. ed.) Upper Saddle River, NJ: Prentice Hall.

Higgins, E. T. (1997). Beyond Pleasure and Pain. American Psychologist,52(December), 1280-1300. Higgins, E. T., Christopher, J. R., Roney, E. C., \& Hymes, C. (1994). Ideal Versus Ought Predilections for Approach and Avoidance - Distinct Self-Regulatory Systems, Journal of Personality and Social Psychology, 66, 276-286.

James, B. R. (2004). Probabilidade: um curso em nível intermediário. (3. ed.) Rio de Janeiro: IMPA. Johnson, J., \& Tellis, G. (2005). Blowing Bubbles: Heuristics and Biases in the Run-Up of Stock Prices. Journal of the Academy of Marketing Science, 33(4), 486-503.

Kahneman, D., \& Tversky, A. (1972). Subjective Probability: A Judgment of Representativeness. Cognitive Psychology, 3, 430-454.

Koehler, J. J., \& Conley, C. A. (2003). The "hot hand" myth in professional basketball. journal of Sport \& Exercise Psychology, 25, 253-259.

Kudryavtsev, A., Cohen, G., \& Hon-Snir, S. (2013). "Rational" or "Intuitive": Are Behavioral Biases Correlated Across Stock Market? Contemporary Economics. 7(2), 31-53.

Kuhnen, C. M., \& Knutson, B. (2011). The Influence of Affect on Beliefs, Preferences, and Financial Decisions. The Journal of Financial and Quantitative Analysis, 46(3), 605-626.

Lee, K., Choi, J., \& Li, Y. (2014). Regulatory focus as a predictor of attitudes toward partitioned and combined pricing. Journal Of Consumer Psychology (Elsevier Science), 24(3), 355-362.

Lehmann, D. R., Gupta, S. \& Steckel, J. H. (1998). Marketing Research. Prentice-Hall.

Liberman, N., Idson, L. C., Camacho, C. J., \& Higgins, E. T. (1999). Promotion and Prevention Choices Between Stability and Change. Journal of Personality and Social Psychology, 77(December), 11351145.

Loewenstein, G., \& Lerner, J. S. (2003). The Role of Affect in Decision Making. In: R. J. Davidson, K. R. Scherer, \& H. H. Goldsmith (Eds.), Handbook of Affective Sciences. (pp. 619-642). New York: Oxford University Press.

Loh, R. K., \& Warachka, M. (2012). Streaks in Earnings Surprises and the Cross-Section of Stock Returns. Management Science, 58(i7), 1305-1321.

Lyons, J., Weeks, D. J., \& Elliott, D. (2013). The gambler's fallacy: A basic inhibitory process? Frontiers in Psychology, 4(72), 1-11.

Mourão Júnior, C. A. (2009). Questões em bioestatística: o tamanho da amostra. Revista Interdisciplinar de Estudos Experimentais, v. 1, n. 1, p. 26-28. 
Pallant, J. (2011). SPSS Survival Manual: A Step by Step Guide to Data Analysis using SPSS for Windows (4rd ed.), Open University Press: McGraw-Hill.

Rabin, M., \& Vayanos, D. (2010). The Gambler's and Hot-Hand Fallacies: Theory and Applications. The Review of Economic Studies, 77(2), 730-778.

Roney, C. J. R., \& Trick, L. M. (2003). Grouping and Gambling: A Gestalt Approach to the Gambler's Fallacy. Canadian Journal of Experimental Psychology, 57(2), 69-75.

Roney, C. J. R., \& Trick, L. M. (2009). Sympathetic Magic and Perceptions of Randomness: The Hot Hand Versus the Gambler's Fallacy. Thinking and Reasoning, 15(2), 197-210.

Shadish, W. R., Cook, T. D., \& Campbell, D. T. (2002). Experimental and Quasi-Experimental Designs: For Generalized Causal Inference. New York: Houghton Mifflin.

Shah, J., Higgins, E. T., \& Friedman, R. S. (1998). Performance Incentives and Means: How Regulatory Focus Influences Goal Attainment. Journal of Personality and Social Psychology, 74(February), 285293.

Silva, D. M. L. (2011). Relação Entre Atingimento de Meta e Autorregulação na Decisão de Compra de Produto de Consumo. Tese de doutorado, Universidade Federal do Paraná, Curitiba, PR, Brasil.

Sirri, E., \& Tufano, P. (1998). Costly Search and Mutual Fund Flows. Journal of Finance, 53, 15891622.

Smith, G., Levere, M.; \& Kurtzman, R. (2009). Poker Play Behavior After Big Wins and Big Losses. Management Science, 55(9), 1547-1555.

Suetens, S., \& Tyran, J. R. (2012). The Gambler's Fallacy and Gender. Journal of Economic Behavior \& Organization. 83(1), 118-124.

Trope, Y, \& Liberman, N. (2010). Construal-level theory of psychological distance. Psychological Review, 117, 440-463.

Tversky, A., \& Kahneman, D. (1971). Belief in the law of small numbers. Psychological Bulletin, 76(2), 105-110.

Tversky, A., \& Kahneman, D. (1974). Judgment Under Uncertainty: Heuristics and Biases. Science, New Series, 185(4157), 1124-1131.

Tversky, A., \& Kahneman, D. (2000). Judgment Under Uncertainty: Heuristics and Biases. In: T. Connolly, H. R. Arkes, \& K. R. Hammond (Eds.) Judgment and Decision Making: An Interdisciplinary Reader. (2a ed). New York: Cambridge University Press.

Viacava, J. J. C. (2012). A Influência das Avaliações de Satisfação e das Variações de Preço nas Decisões de Compra nos Serviços Bancários Brasileiros. Dissertação de mestrado, Universidade Federal do Paraná, Curitiba, PR, Brasil.

Xi, Z., Scholer, A. A., \& Higgins, E. (2014). In Pursuit of Progress: Promotion Motivation and Risk Preference in the Domain of Gains. Journal Of Personality \& Social Psychology, 106(2), 183-201.

Xu, J., \& Harvey, N. (2014). Carry on winning: The gamblers' fallacy creates hot hand effects in online gambling. Cognition, 131, 173-180.

Xue, G., Lu, Z., Levin, I. P., \& Bechara, A. (2011). An fMRI study of risk-taking following wins and losses: Implications for the gambler's fallacy. Human Brain Mapp, 32(2), 271-281.

Yaari, G., \& Eisenmann, S. (2011). The hot (invisible?) hand: Can time sequence patterns of success/failure in sports be modeled as repeated random independent trials? PLOS ONE, 6(10).

Yuan, J., Sun, G.-Z., \& Siu, R. (2014). The lure of illusory luck: How much are people willing to pay for random shocks. Journal of Economic Behavior \& Organization, 106(October), 269-280. 